\title{
A Study on Logistics Issues faced by Distributors in Food processing industry in Gujarat
}

\author{
Dr. Richa Pandit \\ Associate Professor Shri Chimanbhai Patel Institute of Management \& Research, \\ Ahmedabad, Gujarat 380015 \\ Email - richapandit@cpi.edu.in
}

\begin{abstract}
The speed and complexity of the global economy has opened up eyes for contemporary logistics and supply chain practitioners. Logistics and Supply Chain Management (LSCM) is introduced to be an integrated approach comprising of different functions and processes within a firm. It is extended to a network of various participants fulfilling increasing customer expectation in terms of cost minimization and benefit maximization. The Indian food industry is poised for huge growth, increasing its contribution to world food trade every year. In India, the food sector has emerged as a high-growth and high-profit sector due to its immense potential for value addition, particularly within the food processing industry. The study encompass objective of studying the logistics issues faced by the distributors in Gujarat. A systematic research approach with the descriptive design of research and non probability convenience sampling technique is used in this study. The research highlights that modes of transportation and inventory management are the two major issues faced by the distributors of food processing industry.
\end{abstract}

Key Words: Logistics Management, Food Processing Industry and Supply Chain Management.

\section{Introduction:}

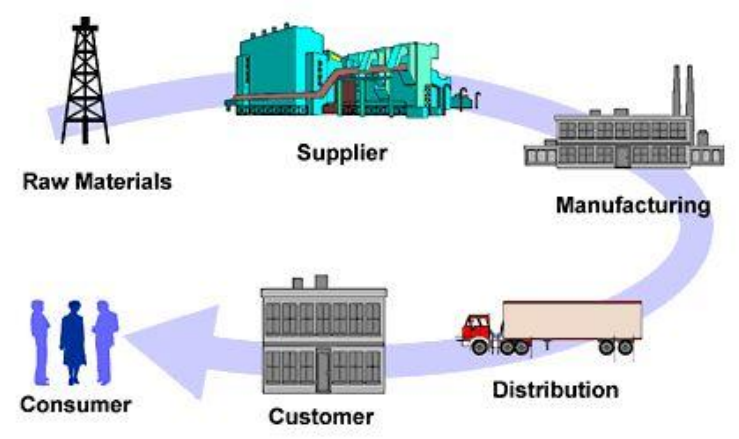

(Source: http://organizations.weber.edu/sascm/supply_chain.bmp) 
Logistics and Supply Chain Management (LSCM) is a process of planning, implementing and controlling an effective flow and storage of goods, services and related information from the point of origin to the point of consumption for the purpose of conforming to customer requirements.

The Indian food industry is poised for huge growth, increasing its contribution to world food trade every year. In India, the food sector has emerged as a high-growth and high-profit sector due to its immense potential for value addition, particularly within the food processing industry. The food industry, which is currently valued at US\$ 39.71 billion! is expected to grow at a Compounded Annual Growth Rate (CAGR) of 11 per cent to US\$65.4 billion by 2019. Food and grocery account for around 31 per cent of India's consumption basket.

The Indian food and grocery market is the world's sixth largest, with retail contributing 70 per cent of the sales. Food has also been one of the largest segments in India's retail sector, which was valued at US\$ 490 billion in 2013@. The Indian food retail market is expected to reach Rs 61 lakh crore (US\$ 894.98 billion) by 2020.

The Indian food processing industry accounts for 32 per cent of the country's total food market, one of the largest industries in India and is ranked fifth in terms of production, consumption, export and expected growth. It contributes around 14 per cent of manufacturing Gross Domestic Product (GDP), 13 per cent of India's exports and six per cent of total industrial investment. Indian food service industry is expected to reach US\$ 78 billion by 2018.The Indian gourmet food market is currently valued at US\$ 1.3 billion and is growing at a Compound Annual Growth Rate (CAGR) of 20 per cent. India's organic food market is expected to increase by three times by 2020 .

According to the data provided by the Department of Industrial Policies and Promotion (DIPP), the food processing sector in India has received around US\$ 6.82 billion worth of Foreign Direct Investment (FDI) during the period April 2000-March 2016. The Confederation of Indian Industry (CII) estimates that the food processing sectors have the potential to attract as much as US\$ 33 billion of investment over the next 10 years and also generate employment of nine million person-days.

\section{Literature Review}

Groznik primarily point out that an efficient Logistics and Supply Chain Management is crucial for survival in a turbulent world. As observed by Deman \& Tuyishime, India is an emerging economy with major challenges to managing an effective supply chain system. They argue that the concept of SCM is still nascent in the country and explore the opportunities and tools of effectively managing the same. Again, Srivastava provides with a snapshot of present logistics infrastructure in India. In his study, he insists upon collaboration and strategic alliances for successfully managing the show. Reddy \& Raju perceive that an efficient supply chain makes business houses competitive and sustainable. However, they justify that regardless of extensive

research carried out in the area of Supply Chain Management all over the world, SCM practices have not yet been well adopted in developing nations like India. 
In this context, Kearney persists upon creating competitive advantage through effective supply chain and logistics system in the country. However, Mangal in his paper suggest the ways to achieve Total Quality Management using SCM principles in process industries. Reddy attempts at outlining the role of Information Technology towards making an optimal logistics decision. He indicates that an up-to-date and state-of-the-art technology (namely auto ID technique, RFID) along with relevant management tools like ERP, CRM and SRM have to be utilized for an enhanced performance of logistics network in the country.

Further, Jain, Dangayach, Agarwal and Banerjee make an extensive review of available literatures on Supply Chain Management with a unique classification scheme. Based on this review, they attempt to identify relevant issues on logistics and SCM framework in India highlighting probable area of research in near future. Put differently, Olga talks about sustainable supply chain and embodies in his paper an overview of relevant concepts and theories in that regard. He also contributes towards a framework development for future area of research. Agarwal is very much attentive on recent challenges in logistics management in India and becomes concerned about how to meet up these challenges where there happens to be an informal economy for last few decades. In the same outlook, Singh reveals that SCM influences about $64 \%$ of all costs in a manufacturing company. He tries to understand the present status of Supply Chain Management in Indian companies and recommends the attributes for implementation of a successful chain.

Murthy throws light upon global trend in Logistics Management and indicates salient features of Indian supply chain. He also meaningfully highlights the initiatives taken by regulatory bodies for an improved SCM network in the country. Nagappa and Metri put forward an opinion that managing supply chain efficiently has become a way of improving competitiveness by reducing uncertainty and enhancing customer service. Sood carefully examines the apparent challenges in Indian retail industry. He feels that logistics and supply chain form a major part of sustenance of any retail venture. On a long term basis, there would be a need to build up a flexible supply chain-he infers further. Considering a Green Economy,

Mohanty and Prakash substantiate the importance of Green Supply Chain Management (GSCM) practices in Micro, Small and Medium Enterprises (MSMEs) in India. They capture a fact that although the studies in said area has grown up in recent times, the literature is yet to furnish an accepted explanation for why green practices are to be manifested in supply chain and logistics framework. Gurumurthy, Soni, Prakash and Badhotiya have done a pragmatic review on Supply Chain Management research and conclude by documenting the growing significance of logistics practices within Indian business domain. In addition, Bora and Adhikary provides with an empirical insight on various supply chain challenges in India. Their study infers that a smart supply chain management is vital to industrial firms operating in modern competitive world. Thinking beyond boundary, Adhikary and Bhutia in their study make an attempt to examine a

variety of export related services and logistics infrastructure with respect to trade from Northeast Region of India. They indicate a future agenda in upgrading logistical network for promotion of international trade in the region. Yet again, Bora aims at having an overview on the current status of logistics industry and supply chain practices in India. 


\section{Research Objectives}

- To find out the logistics problems are associated with the type of products or not.

- To find out whether geographical area affect the modes of transportation or not.

- To find out the areas of improvement in the logistics management.

- To study the logistics management in the food processing industry.

\section{Research Methodology}

Descriptive research design has been considered as a suitable methodology for present study and for data analysis because descriptive research describes data and characteristics about the sample being studied. However, it does not answer questions about e.g.: how/when/why the characteristics occurred, which is done under analytic research. According to C. R. Kothari, most of the social research comes under category of descriptive research. Source of data includes both primary and secondary data. The primary data was collected through Structured Questionnaire. Questionnaire was framed and survey was conducted for collecting the primary data for study and analysis and the Secondary Data was collected from magazines, journals, management books and websites.

Survey Method has been considered as a suitable data collection method for present study because it enables to get proper response to complex questions. Population is any set of persons that possesses at least one common characteristic. Distributer of Food Processing Industry products of Ahmedabad, Rajkot, Baroda and Surat. Sampling methods are classified as either probability or non-probability. In probability samples, each member of the population has a known non-zero probability of being selected. Probability methods include random sampling, systematic sampling, and stratified sampling. In non-probability sampling, members are selected from the population in some nonrandom manner. These include convenience sampling, judgment sampling, quota sampling, and snowball sampling. The advantage of probability sampling is that sampling error can be calculated. Sampling error is the degree to which a sample might differ from the population. When inferring to the population, results are reported plus or minus the sampling error. In non-probability sampling, the degree to which the sample differs from the population remains unknown. In the present study, non-probability Convenience sampling is used.

Sampling frame is the actual set of units from which a sample has been drawn: in the case of a simple random sample, all units from the sampling frame have an equal chance to be drawn and to occur in the sample. In the ideal case, the sampling frame should coincide with the population of interest. Distributer of FMCG products of Ahmedabad, Rajkot, Baroda and Surat. 200 distributors were surveyed for the purpose of collecting the data. Structured questionnaire was used as data collection tool.

\section{Data Analysis}

Objective 1: To find out problems are associated with the type of products or not .logistics.

\section{CHI - SQAURE}




\section{Hypothesis}

H0: Logistics problems and type of products are independent to each other.

H1: Logistics problems and type of products are dependent to each other.

\begin{tabular}{|l|l|l|l|}
\hline Sr. No & Independent Variable & Dependent Variable & Sig value \\
\hline 1 & type of products & Logistics problems & 0.001 \\
\hline
\end{tabular}

Significance value stated in above table is less than 0.05 therefore, alternative hypothesis is accepted which infers that Logistics problems and type of products are dependent to each other.

Objective2: To find out whether geographical area affect the modes of transportation or not.

\section{ONE WAY ANOVA}

H0: There is no significant difference between the geographical area and the modes of transportation (Road/Rail/Sea/Air/Hybrid).

H1: There is a significant difference between the geographical area and the modes of transportation. (Road/Rail/Sea/Air/Hybrid)

\begin{tabular}{|c|c|c|c|}
\hline Sr. No & Independent Variable & Dependent Variable & Sig value $P$ \\
\hline 1 & \multirow{5}{*}{ Geographical Area } & Road & 0.041 \\
\hline 2 & & Rail & 0.017 \\
\hline 3 & & Sea & 0.012 \\
\hline 4 & & Air & 0.058 \\
\hline 5 & & Hybrid & 0.007 \\
\hline
\end{tabular}

Significance value stated in above table is less than 0.05 therefore, alternative hypothesis is accepted which infers that Geographical area and road they both are dependent on each other. Significance value stated in above table is less than 0.05 therefore, alternative hypothesis is

accepted which infers that Geographical area and rail they both are dependent on each other. Significance value stated in above table is less than 0.05 therefore, alternative hypothesis is accepted which infers that Geographical area and sea they both are dependent on each other. Significance value stated in above table is less than 0.05 therefore, alternative hypothesis is 
rejected which infers that Geographical area and air they both are not dependent on each other. Significance value stated in above table is less than 0.05 therefore, alternative hypothesis is accepted which infers that Geographical area and Hybrid they both are dependent on each other.

Objective 3: To find out the areas of improvement in the logistics management.
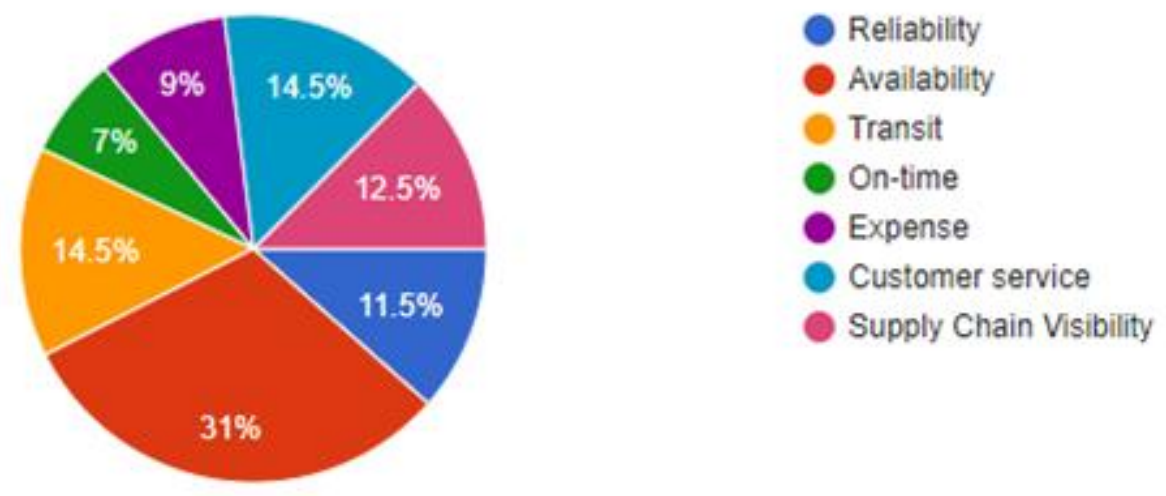

According to the responses, $31 \%$ of the people think that they have to improve on availability part, $14.5 \%$ of the people think to improve the Transit \& Customer service, $12.5 \%$ respondent thinks to improve Supply chain visibility, $11.5 \%$ respondent think to improve Reliability area, $9 \%$ and $7 \%$ respondent thinks to improve Expense \& on time areas.

Objective 4: To study the logistics management in the food processing industry.
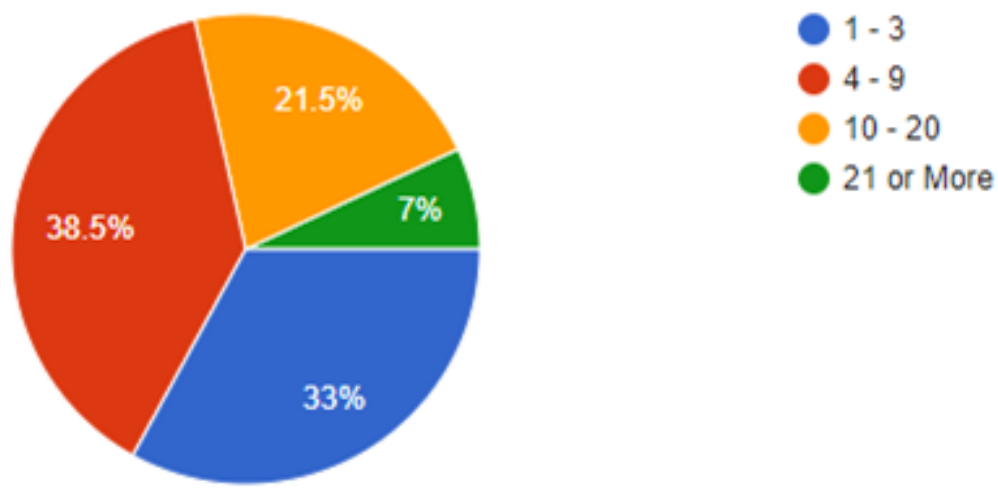

According to responses $38.5 \%$ people are currently managing 4-9 carriers, $33 \%$ of the distributer are currently managing in 1-3 carriers, $21.5 \%$ of the distributer are managing in 10-20 carriers \& rest $7 \%$ are managing in more than 20 carriers. 


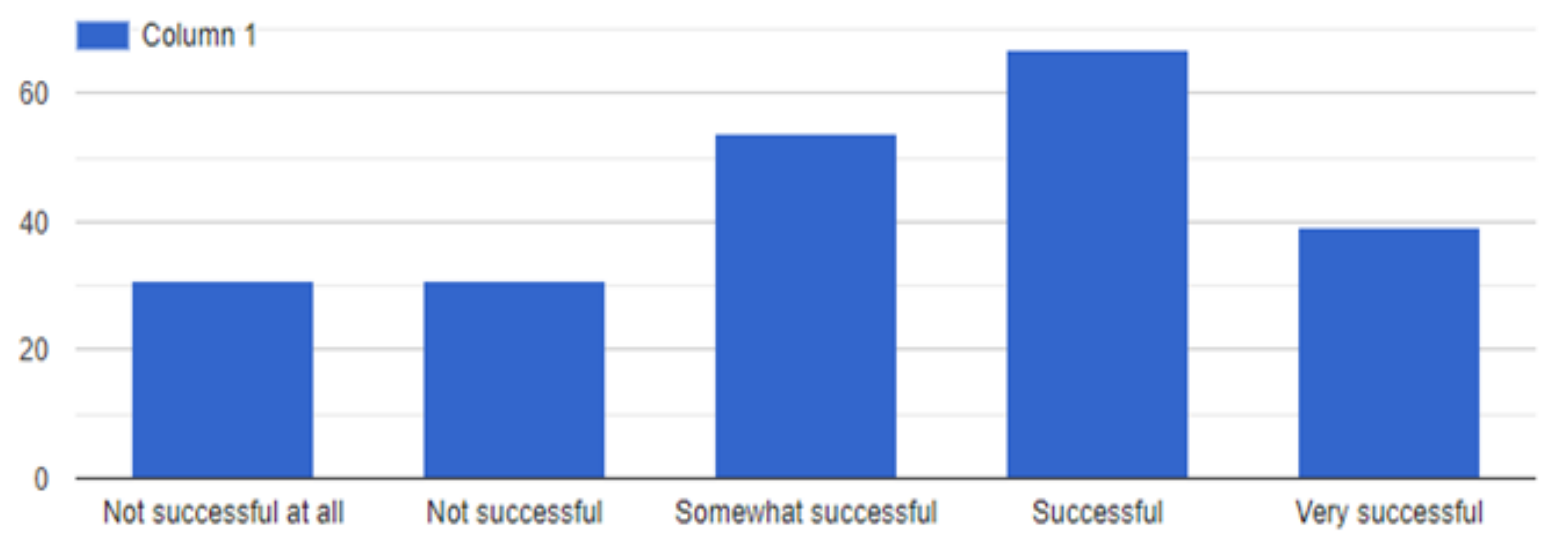

According to the respondent more then $60 \%$ are people are successful in managing supply chain in general, $60 \%$ are people are successful in managing supply chain in general, more than $50 \%$ are people are somewhat successful in managing supply chain in general, almost $40 \%$ of people are very successful in managing supply chain in general, $30 \%$ \& $30 \%$ of people are not successful and not successful at all in managing supply chain in general.

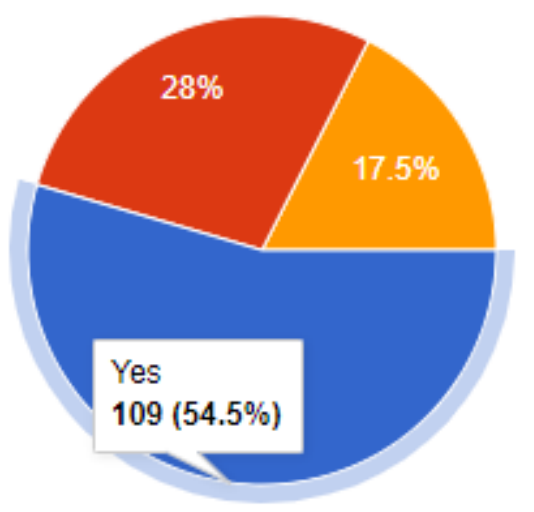

According to the respondent, majorly 54.5\% of the distributer thinks company should keep warehouse for keeping food fresh and consumable, whereas $28 \%$ of the distributer suggests not 
to keep and $17.5 \%$ of the distributers responses as maybe to keep the warehouse for keeping food fresh and consumable.

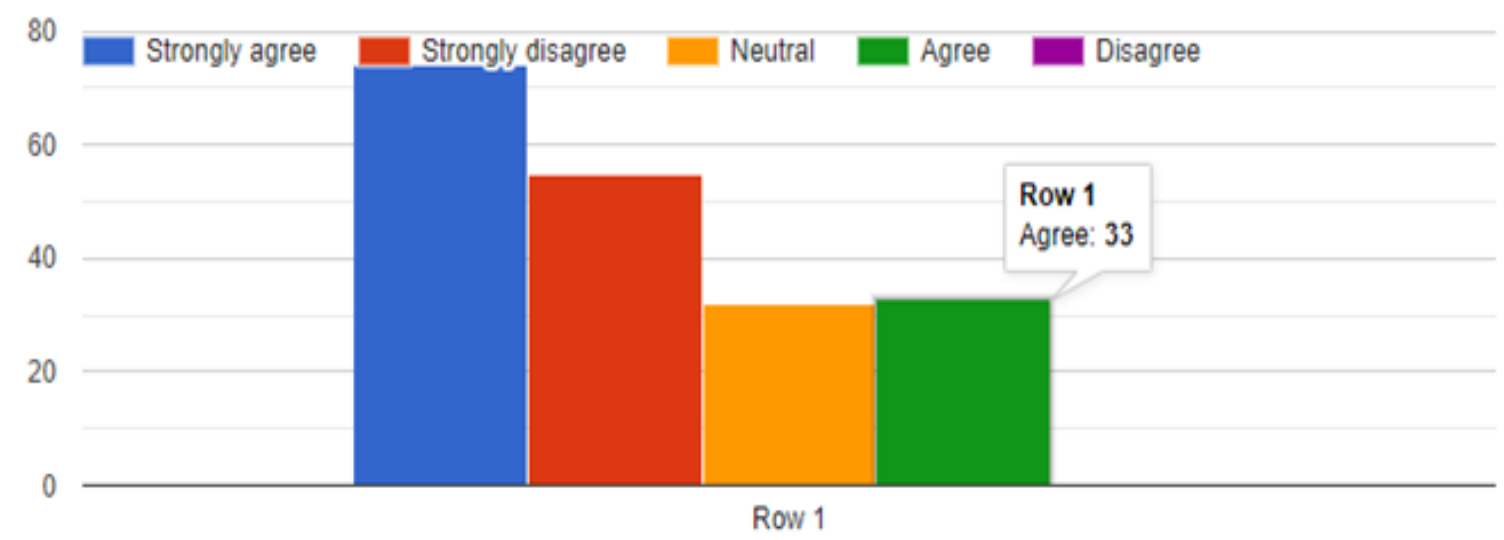

According to the responses, $70 \%$ of the distributers strongly agree that their customers are satisfied with the services provided, $55 \%$ of the distributers strongly disagree that their customers are satisfied with the services provided, $50 \%$ of the distributers suggests neutral - that their customers are satisfied with the services provided, $33 \%$ of the distributers agree that their customers are satisfied with the services provided, $30 \%$ of the distributers disagree that their customers are satisfied with the services provide

\section{Findings}

- Logistics problem greatly depend upon the type and nature of the product. Logistics problem are more in perishable then non perishable products.

- Selection of mode of transportation is influenced by the geographical area in which the distributor operates except Air Cargo.

- Inventory management is the major issue in food processing industry that leads to logistics management problem.

- According to the distributors, food processing company are in a moderately organized way managing logistics of its products.

- Majority of the distributor believes that the company should have well managed warehousing system to keep the food fresh and consumable.

- Despite of the problem in logistic management in food processing industry, majority of distributor are seems to be satisfied with the company. 


\section{Conclusion and Future Direction}

Food processing industry has flourished significantly in the recent years. Industry deals with all the three categories of the products : perishable, semi-perishable and non-perishable therefore distribution channels with all the levels are very important from the operations point of view. Distributers play very important role for the smooth functioning of the industry and the same has been studies in these research. Efficiency of logistics management in food processing industry are found to the moderate. But overall there is a satisfaction among a channel partners in the food processing industry.

The issue of logistics management in India to become internationally sustainable is to capitalize on advancement in technology which at one point of time happened to be a facilitator just for doing business, now becomes an enabler for aligning to global world. As such, what have been outlined through this study are few observations at micro level only. There are many more areas and issues that have not been able to be spaced out here and many, which that the respective stake- holders and reformers would be open to. All that require mentioning is that there is a governing body in place, which is, or if not, should be committed to deliver on its promise of mapping Indian logistics in global platform. That's why, it's a time to think, plan, manage and re-act and together we could envisage in ushering in a new logistics and supply chain era in the country.

\section{References}

1. Adhikary Anindita and Bhutia Tashi Yangzum, 2011, North East India's Trade Logistics : Challenges Ahead, International Conference on Advances in Supply Chain and Manufacturing Management (ASCMM 2011), IIT Kharagpur, p-109.

2. Anand Gurumurthy, Soni Gunjan and Prakash Surya, 2013, Review on Supply Chain Management Research-An Indian Perspective, IIM Kozhikode Society \& Management Review, Vol-2, No-1, Pp-1- 19, SAGE Publication.

3. Bora Bedanta and Adhikary Anindita, 2014, Supply Chain Challenges in India-An Empirical Insight, The International Journal of Business \& Management, Vol.02, Issue.04, ISSN: 2321-8916, Pp-31-37.

4. Bora Bedanta, 2016, Indian Logistics Industry-A Perspective for Augmentation, International Conference on E-Business and Supply Chain Competitiveness (EBSCC2016), IIT Kharagpur, p-440.

5. Deman Julie and Tuyishime Jean, 2008-2009, Supply Chain Management in Emerging Markets: India, Master Thesis, Faculty of Economics and Business Administration, University of Ghent.

6. Jain Jinesh, Dangayach G. S., Agarwal G., Banerjee Soumya, 2010, Supply Chain Management : Literature Review and Some Issues, Journal of Studies on Manufacturing, Vol-1, Iss-1, Pp-11-25.

7. Kearney A.T., May, 2013, Creating Competitive Advantage through Supply Chain: Insights on India, CSMP, India, www.google.com.

8. Mangal Dharamvir, Jan, 2013, Supply Chain Management-A Quality Improving Tool in Process Industries, International Journal of Application or Innovation in Engineering \& Management,Vol-2, Iss-1, ISSN : 2319 - 4847. 
9. Mohanty R.P. and Prakash Anand, Sept, 2013, Green Supply Chain Management Practices in India: An Empirical Study, Production Planning \& Control: The Management of Operations, Taylor \& Francis Group

10. Murthy Nagaraja H.L., 2012, Recent Trends in Global Supply Chain Management, www.IndianFaculty.com

11. Nagappa A. N. and Metri Bhimaraya A., 2000, Supply Chain Management: Opportunities and Challenges, www.google.com

12. Olga Chkanikova, 2012, Sustainable Supply Chain Management: Theoretical Literature Overview, IIIEE Working Paper, ISBN: 978-91-88902-87-0. Agarwal Vineet, How to meet Supply Chain Challenge, Business Lines, The Hindu.

13. Reddy Ramana Venkata M. and Raju V.S., 2013, Issues and Challenges of Supply Chain Management in India, International Journal of Mechanical and Production Engineering, ISSN: 2315-4489, Vol-2, Iss-1.

14. Reddy Ramana Venkata M., July, 2012, Status of Supply Chain Management in India, International Journal of Emerging Technology and Advanced Engineering, ISSN: 22502459, Vol-2, Iss-7.

15. Singh Rakesh, July, 2004, Supply Chain Management: The Indian Scenario, www.google.com Sood Aashish, 2011, Supply Chain Challenges in Indian Retail, www.Ideasmakemarket.com

16. Srivastava K, Logistics and Supply Chain Management Practices in India, 6th Global Conference on Business and Economics, ISBN: 0-9742114-6-X.

17. Trkman Peter and Groznik Ales, 2010, Current Issues and Challenges of Supply Chain Management, European and Mediterranean Conference on Information Systems, Abu Dhabi, UAE. 